\title{
HYPOCHOLESTEROLEMIA IN CLINICALLY SERIOUS CONDITIONS - REVIEW
}

\author{
Pavel Vyroubal ${ }^{a *}$, Carlo Chiarla ${ }^{\mathrm{b}}$, Ivo Giovannini ${ }^{\mathrm{b}}$, Radek Hyspler ${ }^{\mathrm{a}}$, Alena Ticha ${ }^{\mathrm{a}}$, \\ Dana Hrnciarikova ${ }^{\mathrm{a}}$, Zdenek Zadak ${ }^{\mathrm{a}}$
}

\author{
a Department of Gerontology and Metabolism, Faculty Hospital and Faculty of Medicine in Hradec Kralove, Sokolska 581, \\ Hradec Kralove, Czech Republic \\ ${ }^{b}$ Centro de Studio per la fissiopatologia, Université Cattolica del S.Cuore, L.go A.Gemelli 8-00168 Roma, Italy \\ e-mail:pavel.vyroubal@seznam.cz
}

Received: October 21, 2008; Accepted (with revisions): August 5, 2008

Key words: Cholesterol/Hypocholesterolemia/Hypolipoproteinemia/SIRS/Cytokines/Polytrauma/Sepsis/Critically ill

Background: Cholesterol is an essential component of cell membranes, precursor of steroids, biliary acids and other components of serious importance in live organism. Cholesterol synthesis is a complicated and energy-demanding process. Real daily need of cholesterol and mechanisms of decline cholesterol levels in critical ill are unknown. During stressful situations a significant hypocholesterolaemia may be found. Hypocholesterolemia has been known for a number of years to be a significant prognostic indicator of increased morbidity and mortality connected with a whole spectrum of pathological conditions. The aim of article is the elucidation of the role and importance of hypocholesterolaemia during the intensive care. .

Methods and Results: We examined studies that are engaged in problems of hypocholesterolemia in critically ill. Very low levels of total as well as LDL cholesterol are most frequently found in serious polytrauma, after extensive surgery, in serious infections, in protracted hypovolemic shock. It is still not clear whether hypocholesterolemia reflects only a serious metabolic disorder, which results from a life-threatening condition, or whether it has an active role in evolution and outcome.

Conclusions: Hypocholesterolemia is commonly observed in critically ill patients. Nevertheless, it is not known whether it is a secondary manifestation of disease, or whether it actively contributes to deterioration of the disease. Although the contribution of hypocholesterolemia to mortality is modest compared with known risk factors such as increased severity of illness and the development of nosocomial infection, low serum lipid concentrations represent a potential therapeutic target in sepsis.

\section{INTRODUCTION}

Cholesterol is an inevitable component of almost all phospholipid membranes in the human organism. It occurs in both the free and ester form of cholesterol and fatty acids. Free cholesterol is a component of cell membranes. In plasma, about one third of cholesterol is free, and two thirds exist as esters containing linoleic and oleic acids ${ }^{1}$. Intracellularly, the stockpool of cholesterol is formed by its esters with oleic, palmitic and linoleic acids in some cells. Cholesterol in the organism originates both from the external environment by absorption from the digestive tract and by synthesis de novo from acetyl-CoA. Under normal circumstances, a significant portion of the required amount of cholesterol is obtained from food.

Absorption of cholesterol is a complex process performed by specific carriers on the brush border of enterocytes in the jejunum. The crucial transporter is Niemann-Pick C1 like 1 protein - NPC1L1 (ref. ${ }^{2}$ ). Knockout mice (NPC1L1 null) have large reduction $(>90 \%)$ in cholesterol absorption ${ }^{3}$. 1 protein - NPC1L1?? is a target molecule for widely used cholesterol absorption inhibitor ezetimibe and it probably cannot discriminate between cholesterol and structurally related phytosterols. These compounds are effectively transported back into the lu- men by ATP-binding cassette $(\mathrm{ABC})$ cotransporters $\mathrm{G} 5$ and G8 (ref. ${ }^{4}$ ). Molecules ABC G 5,8 are also expressed on the bile side of hepatocytes and enable transport of phytosterols and cholesterol from hepatocytes into bile. Mutations in ABC G5,8 cause sitosterolemia, a rare disorder connected to grossly elevated phytosterol levels in the organism, and characterised by early development of atherosclerosis. There are also other transporters expressed on the brush-border membrane of enterocytes such as SR-BI (ref. ${ }^{5}$ ), CD-36 (ref. ${ }^{6}$ ) or aminopeptidase $\mathrm{N}$ ( ref. $^{7}$ ) but their exact role remains to be elucidated. Cholesterol absorption effectiveness ranges around 50$60 \%$ depending on the kind of diet and its cholesterol content. During the day, on average about 250 - $500 \mathrm{mg}$ of cholesterol is absorbed in this way, and this amount is regulated by enterocyte nuclear receptors. Liver X receptor sensing intracellular oxysterol (LXR) regulates gene expression of $\mathrm{ABC}$ transporters ${ }^{8}$, and nuclear receptors PPAR alpha, beta/delta, gamma regulate NPC1L1 transporter ${ }^{9}$.

Under physiological conditions, de novo synthesis in the whole body exceeds absorption of cholesterol from food several times. All cells of the human body except nucleus-free erythrocytes are able to synthesize cholesterol de novo and the product is dedicated for intracellular use. 
Cholesterol dedicated for plasma lipoproteins (additional supply for many types of cells) is synthesized in the liver and in the distal part of the small intestine ${ }^{10}$.

The lack of intracellular cholesterol is registered by SREBP cleavage-activating protein (SCAP) which contains a sterol-sensing domain. At low intracellular sterol concentrations, SCAP translocates the inactive, membrane-bound form of SREBP (sterol element binding protein) to the Golgi, where two distinct proteolytic cleavage steps convert it to its nuclear and transcriptionally active form ${ }^{11}$. Following activation, the SREBPs translocated to the nucleus dimerize and interact with cognate regulatory sequences, the sterol regulatory elements (SRE's) to transactivate genes - the LDL receptor protein, Niemann-Pick C1 protein (NPC1, crucial for intracellular cholesterol trafficking) and enzymes necessary for cholesterol synthesis (HMG-CoA synthase and reductase, farnesyl diphosphate synthase, squalene synthase) ( ref. $^{12}$ ). Cholesterol synthesis takes place initially in the cytoplasm (up to the hydrocarbon intermediate squalene), and then in the endoplasmic reticulum (squalene cyclisation and subsequent steps). The key regulatory enzyme is $\mathrm{HMG}$ CoAreductase, also a target for competitive pharmacological inhibitors - statins. Complete biosynthesis (Fig. 1) of cholesterol amounts to nearly 200 enzymatic processes, and thus it is not surprising that higher organisms at the top of the food pyramid make use of cholesterol synthesized by lower organisms, thus saving the load connected with the hugely complicated and energy-demanding cholesterol synthesis. Thus, many tissues prefer cholesterol from plasma lipoproteins rather than their own intracellular synthesis. Also from this viewpoint it is logical that cholesterol synthesis, because of its energy demands, takes place mainly in the night between 2 and 4 a.m., in the period of physical rest of the organism. The maximal synthesis of cholesterol in a healthy human being varies in the range of 500- $1000 \mathrm{mg}$ a day.

Absorbed cholesterol from the diet is a component of chylomicrons and is directed as chylomicron remnants towards the liver. The hepatic cholesterol pools originating from chylomicron remnants (dietary cholesterol) and de novo synthesised cholesterol are combined and excreted as VLDL lipoproteins. Intravascularly, VLDL converts to LDL lipoprotein and this particle is a major source of cholesterol for many tissues, specifically those undergoing frequent cell divisions ${ }^{1}$. Some types of cells (mostly steroidogenic and hepatocytes) are also able to obtain cholesterol esters from HDL particles using specific cell surface receptors - scavenger receptor class B type I (SR-BI) $\left(\right.$ ref. $\left.^{13}\right)$.

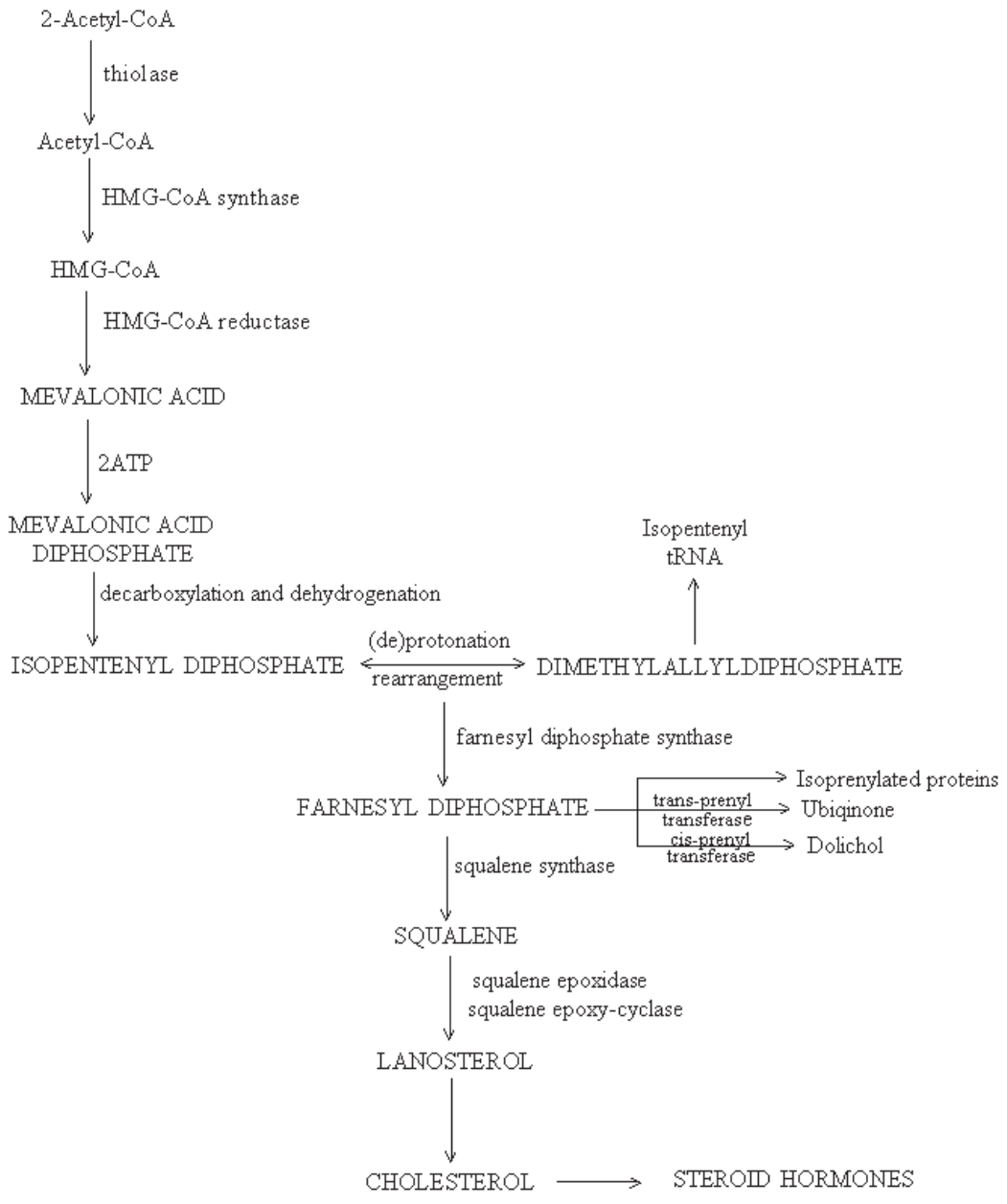

Fig. 1. Synthesis of cholesterol and its intermediates 
The transport of cholesterol from extrahepatic tissues to the liver is termed "reverse cholesterol transport". Free (non-esterified) cholesterol effluxes to extracellular acceptors, most notably phospholipid/apoA-I disks (preB-HDL). This process is directly (or indirectly through phospholipid efflux) dependent on functional ABC A1 receptor. Cholesterol that associates with apoA-I/phospholipid disks is a substrate for lecithin-cholesterol acyl transferase (LCAT). LCAT transfers a fatty acyl chain from phosphatidylcholine to cholesterol, forming cholesteryl ester. The cholesteryl ester partitions into the hydrophobic core of the lipoprotein, thus forming spherical HDL particles. These particles can then deliver cholesteryl ester to the liver and steroidogenic tissues ${ }^{14}$.

The major excretory pathway for cholesterol is bile formation. Cholesterol is a substrate for bile acid formation. There are two major pathways of bile acid synthesis - neutral ("classic") and acidic ("alternative"). In the neutral, or "classic" pathway, synthesis begins with hydroxylation of the cholesterol molecule in the $7 \alpha$ position by microsomal cholesterol $7 \alpha$-hydroxylase (CYP7 $\alpha 1$ ); in the acidic, or "alternative" pathway, bile acids are hydroxylated in position 27 by cholesterol 27-hydroxylase (CYP-27) (ref. ${ }^{15}$ ). While people with inborn errors in the CYP7 $\alpha 1$ pathway display a hypercholesterolemic phenotype and resistance to cholesterol lowering agents, CYP-27 deficiency is responsible for a severe clinical picture, characterized by neurological impairment and accelerated atherosclerosis ${ }^{15}$. Bile acids achieve multiple physiological functions: they are mandatory for lipid digestion and absorption in the intestine; they represent the end product of cholesterol catabolism; they constitute the most important molecules to drive bile formation and flow, a property otherwise termed "choleretic activity". Cholesterol itself is also secreted in bile, stored in the gallbladder and expelled in the intestine upon feeding. Thus, intraluminally there is almost always more cholesterol from bile than from the $\operatorname{diet}^{10}$. At present, the only recognized disposal mechanism of body cholesterol is through biliary excretion. The liver is thereby the main source of both cholesterol synthesis and disposal.

Cholesterol is crucial for several reasons. 1. It is the principal building block of cell membranes. 2. It plays a vitally important role in human metabolism. There are signalling proteins which require a covalent bond to cholesterol at their C-terminal, such as "sonic hedgehog homolog", an important morphogen ${ }^{16}$. Some intermediary products of cholesterol biosynthesis play important regulatory and mediatory roles. They enable the interactions and activity of hydrophilic signal proteins with cell membrane which is lipophilic. The intermediary products of cholesterol synthesis, such as farnesyl diphosphate and geranylgeranyl diphosphate after binding to the hydrophilic signal protein, allow anchoring the aliphatic moiety and the protein into the predetermined part of the lipophilic cell membrane ${ }^{10}$. Therefore it secures anchoring of the signal protein on the surface of the cell and transfer of the signal information to the cell. This is also the way ras-proteins function ${ }^{10}$. Other important by-prod- ucts of the cholesterol synthetic pathway are ubiquinones, which play a decisive role in the maintenance of reduction-oxidation balance and oxidative phosphorylation in cells and, dolichols which are essential in the process of glycoprotein synthesis ${ }^{1}$.

\section{METHODS}

\section{Methods for determination of cholesterol synthesis and absorption}

Existing techniques for measuring cholesterol synthesis are direct and indirect. These represent short-term or long-term pictures. The principle of these techniques is quantification of substrate flux through biosynthetic pathway (in vivo or ex vivo) or determination of concentrations of pathway intermediates.

Sterol balance ${ }^{17}$ provides a direct measure of endogenous biosynthesis rate expressed as the difference between fecal sterol excretion (cholesterol and bile sterols) and cholesterol intake. The necessary presumption is equilibrium of internal sterol pools which can take weeks or months to achieve. Thus long periods are required after shift to a new diet or after illness or injury. Assessment of sterol balance is not a suitable method for measuring cholesterol synthesis in unstable patients (after injuries, major operations and so on). Also, the precision of this method is dependent on complete stool collections and on accurate cholesterol intake assessment.

In the case of cholesterol precursor measurement, the following precursors have been determined: mevalonic acid in blood plasma and 24-hour collections of urine ${ }^{18}$; isoprene in breath ${ }^{19}$; squalene and lathosterol in blood plasma or bile ${ }^{20-21}$. The concentrations of metabolites can provide relative rates of cholesterol synthesis ("snapshots") during time periods in individuals or across treatment groups. Some precursors show circadian variation (isoprene, mevalonic acid, squalene). The apparent disadvantage is the static nature of determination but this can be overcome by frequent non-invasive sampling of breath or urine.

The principle of ex vivo tracer techniques is determination of 3-hydroxy-3-methylglutaryl CoA reductase activity by incorporation of ${ }^{13} \mathrm{C}$ or ${ }^{14} \mathrm{C}$ acetate into sterols or sterol precursors. The assay can be performed with biopsied hepatocytes (limited to surgical procedures) or with circulating mononuclear leukocytes whose presence is unclear however.

Kinetic approaches using injection of ${ }^{13} \mathrm{C}$ - or ${ }^{14} \mathrm{C}$-labelled cholesterol into circulatory pools can follow flux through successive metabolic pools by monitoring the amount of tracer in lipoproteins and other tissues ${ }^{22,23}$. These methods provide detailed information about pool sizes, distribution and formation rates of cholesterol. However, metabolic steady state is required.

Tracer incorporation techniques are the most recent approaches and provide whole-body synthetic rate determination. Current methods include MIDA and deuterium incorporation. In the case of mass isotopomer distribution 
analysis (MIDA), the precursor $\left({ }^{13} \mathrm{C}\right.$-acetate) is infused at a constant rate while relative abundances of mass isotopomers of the product are measured concurrently by gas chromatography-mass spectrometry. The mass isotopomer distribution of the product is determined specifically by the concentration of labeled subunits in the precursor pool from which the polymer was synthesized. Therefore, the observed pattern of excess isotopomer frequencies in the synthesized polymer compared with the expected statistical distribution yields the isotopic enrichment of the true precursor pool. Measurement of isotopic changes during the subsequent post-infusion phase permits determination of the rate constant of decay of higher mass isotopomers.

Limitations of this method include: the precursor pool must be homogeneous, its enrichment constant and fractional synthesis of the product must be constant. Also, a large amount of tracer is required which can perturb the trace pool size and make this method expensive. Typical net synthesis rate obtained by this method is $570 \pm 55 \mathrm{mg}$ / day.

The alternative to MIDA is deuterium incorporation method $^{23}$. The tracer is deuterium oxide and relatively low doses are necessary. Results obtained were shown to yield good agreement with plasma mevalonate as an index of short-term synthesis and this method is capable of detecting changes in synthetic rate over consecutive periods of 12 hours $^{24}$. The cost of tracer is relatively low compared to MIDA technique.

Approaches to studying cholesterol synthesis vary both in the period of measurement and directness of endpoint. Although sterol balance continues to exist as a gold standard, newer techniques, including MIDA and deuterium incorporation, offer advantages of direct measurements over shorter intervals.

To assess cholesterol absorption, two possible methodologies exist. First, double-tracer methods ${ }^{25}$, which determine orally absorbed tracer molecules and their plasma concentration must be compensated for metabolic losses with the aid of second, intravenously applied tracer. Hence, these methods are very expensive.

Second, the phytosterol content of blood plasma can be determined and has been shown to correlate with cholesterol absorption ${ }^{26}$. Phytosterols (e.g. sitosterol, campesterol) are sterols of plant origin which are structurally similar to cholesterol. The absorbed fraction of phytosterols is much smaller than cholesterol (below $10 \%$ ) due to ABC G5,8 receptor activity ${ }^{4}$. The advantage of phytosterol determination is that they can be analysed together with cholesterol precursors.

\section{Mechanisms of cholesterol deficiency}

Hypocholesterolemia is a commonly occurring phenomenon in a number of serious diseases. In 1926 Thannhauser and Schaber $^{27}$ reported an association between low cholesterol and disease. Subsequently, total cholesterol (TC), low-density lipoprotein (LDL), and highdensity lipoprotein (HDL) have been shown to be substantially reduced in patients with many disorders including infections, burns and cancer ${ }^{28-30}$. However, it is not clear what the critical level of cholesterol is. Epidemiological and intervention studies on the relationship of cholesterol and atherosclerosis show that the optimal level of total cholesterol is between the limits of 4.5 to $5.0 \mathrm{mmol} / 1$ and that of LDL cholesterol between the limits of 2.5 to 3.0 $\mathrm{mmol} / 1$. From primate and "primitive" human population studies (human tribes isolated from "civilisation"), optimal plasma concentration of total cholesterol is estimated to be within the range of 3.0 and $4.0 \mathrm{mmol} / 1$ and the corresponding range of LDL cholesterol under $1.8 \mathrm{mmol} / 1$ (ref. ${ }^{31}$ ). A number of papers have reported a critical level of cholesterol of between 2.6 and $3.5 \mathrm{mmol} / 1$ of total cholesterol ${ }^{32-35}$. The cause of the low cholesterol and lipoprotein concentrations in acute illness is most likely multifactorial, involving both decreased synthesis and enhanced catabolism.

It has been observed that concentrations of total and lipoprotein cholesterol decrease markedly in the early phases of critical illness ${ }^{36,37}$. Similar decreases were noted in serum concentrations of HDL and LDL-cholesterol ${ }^{38}$. There is increasing evidence that cholesterol metabolism is related to inflammation ${ }^{39-41}$, and indeed, may regulate and be regulated by proinflammatory cytokines ${ }^{42-45}$. Several studies highlight the relationship between low cholesterol and sepsis ${ }^{46-50}$. In patients who have severe sepsis, total and HDL cholesterol levels fall rapidly and reach $50 \%$ of the recovery levels by day 3 , followed by a slow increase over the next 28 days $^{46}$. Increased levels of proinflammatory cytokines may explain the hypocholesterolemia of acute illness. Decreased synthesis of apoproteins has been demonstrated in hepatic cell lines exposed to tumor necrosis factor- $\alpha$ (TNF- $\alpha$ ), interleukin- $1 \beta$ (IL-1 $\beta$ ) and interleukin 6 (IL-6) $\left(\right.$ ref. $\left.^{51}\right)$. Parenteral administration of pro-inflammatory cytokines has been demonstrated to lower lipid levels ${ }^{52,53}$.

Interleukin-6 (IL-6) concentrations were increased, and there was a significant inverse relationship between IL-6 and total cholesterol concentrations in sepsis. Infection and inflammation induce oxidation of LDL-cholesterol $^{47,54}$. Decrease in HDL-cholesterol may be related to high concentrations of phospholipase $\mathrm{A}_{2}$ ( ref. $^{55}$ ), or to downregulation of the ATP-binding cassette transporter-1 gene $^{56}$.

Increased TNF production in patients with septic shock has been shown to correlate with low total cholesterol concentration and concentrations of apolipoproteins $\mathrm{A}_{1}$ and $\mathrm{B}\left(\right.$ ref. $\left.^{49}\right)$. In companion in vitro studies, TNF increased the degradation of ${ }^{125} \mathrm{I}-\mathrm{LDL}$ in human fibroblasts and endothelial cells, and in HepG2 hepatoma cells ${ }^{35}$. Hypocholesterolemia in critically ill surgical patients has been found to correlate with decrease in plasma proteins and hepatic protein synthesis ${ }^{36}$.

The hypocholesterolemia of acute illness is associated with a moderate increase in triacylglyceride levels caused by an increase in VLDL. The increase in triacylglycerides is a consequence of both decreased clearance and increased hepatic lipogenesis. Animal studies have shown that the hepatic triacylglycerol output can increase 
by $50 \%$ within 2 hours of endotoxin challenge and that both TNF- $\alpha$ and IL-6 increase hepatic lipogenesis ${ }^{57,58}$. Increased adipose tissue lipolysis in response to endotoxin and cytokines provides increased quantities of fatty acid for triacylglycerol synthesis. Muscle and adipose tissue biopsies taken from patients with sepsis have shown reduced lipoprotein lipase activity, and animals with sepsis have shown decreased triacylglycerol clearance when exogenous lipid is

infused $^{59}$. In vitro studies have shown that TNF- $\alpha$ suppresses lipoprotein lipase activity ${ }^{60}$. The clinical significance of moderate hypertriglyceridemia is unclear.

In pathological processes connected with pus formation, there are very large losses of cholesterol, which is eliminated from the organism in the form of disintegrated white blood cells, and this cholesterol cannot be reutilized. The need for cholesterol for cell division and reparative processes may exceed by 5 to 6 times the maximum endogenous cholesterol synthesis ${ }^{32,}{ }^{61}$. In gastroenterological patients in critical conditions with large losses of enteric material from fistulae or ileostomies, a large loss of cholesterol may occur in the form of bile acids, due to interruption of the enterohepatic cycle.

At the other end of the causes of hypocholesterolemia there is a decrease in cholesterol supply. Critically ill patients naturally do not receive peroral food, an important external source of cholesterol. The only possible nutritional support for these patients is parenteral or enteral nutrition. Only some parenteral fat emulsions contain trace amounts of cholesterol (the source of cholesterol is lecithin from the egg yolk used as the stabilizer and emulsifier of intravenously administered fat emulsions). The amount of cholesterol in parenteral nutrition, however, does not exceed $25 \mathrm{mg}$ per day (65 mmol per day) even when fat emulsions with the highest cholesterol content are employed. Undoubtedly, this does not suffice to cover even a fraction of the requirements of the organism in critically ill patients.

\section{Clinical consequences of hypocholesterolemia:}

Hypocholesterolemia is common in critically ill patients. Lipids have been found to play an important role in the reaction of the organism to inflammation and generally in immune functions. Their role in neutralization of lipopolysaccharides, i.e., endotoxins, is of particular importance.

Hypolipidemia reduces competition for binding of lipopolysaccharide (LPS) to lipopolysaccharide-binding protein (LBP), leading to ligation of the CD14 complex and activation of mononuclear cells ${ }^{62-64}$. Conversely, binding of LPS to lipoproteins facilitates delivery of LPS to hepatocytes for detoxification, which if insufficient may lead to increased mononuclear cell activation ${ }^{65}$.

Lipoproteins, especially HDL, bind to and neutralize lipopolysaccharide (LPS). Reconstituted HDL (rHDL), which consists of purified apolipoprotein $\mathrm{A}_{1}$ and phosphatidylcholine is even more effective in neutralizing endotoxin toxicity ${ }^{66}$. In rabbits, administration of rHDL reduced TNF production in response to LPS (ref. ${ }^{67,68}$ ) and reduced TNF production and acidosis after $E$. coli, but not $S$. aureus bacteremia ${ }^{69,70}$. Lipoprotein phospholipids were administered prophylactically in a porcine model of intraabdominal infection ${ }^{71}$. Pretreatment decreased serum endotoxin and TNF concentrations, preserved cardiac output and left ventricular ejection fraction, and attenuated increases in systemic and pulmonary vascular resistances. Of extraordinary importance has been the experimental finding that administration of reconstituted HDL lipoprotein to septic animals significantly increased survival ${ }^{68}$.

Apart from the effect of HDL and rHDL on LPS toxicity, HDL can also influence the fibrinolytic pathway and platelet function directly. Humans who have a high circulating level of HDL have higher tissue-type plasminogen activator and plasminogen activator inhibitor concentrations than subjects with low HDL levels ${ }^{72}$. HDL affects platelet function through interaction with the glycoprotein IIb-IIIa complex, and thereby competes with the binding of fibrinogen to platelets and results in inhibition of platelet aggregation ${ }^{73}$. In a double-blind, placebo-controlled crossover study, LPS was injected following an infusion of rHDL or placebo into healthy male volunteers. In this experiment, rHDL significantly reduced LPS-induced activation of coagulation and fibrinolysis and collagen stimulated platelet aggregation $^{74}$.

Hypocholesterolemia has also been associated with the development of nosocomial infections ${ }^{75-78}$, especially in the postoperative period. Leardi et al. ${ }^{77}$ found the risk of postoperative infection to be $73 \%$ among patients with a total cholesterol concentration of $<2.7 \mathrm{mmol} / \mathrm{L}$, compared with an incidence of infection of $35 \%(p<0.001)$ with a higher cholesterol concentration. These researchers also noted that the cholesterol level fell at the onset of infection, and that a fall in cholesterol was more predictive of infection than an increase in white cell count.

The degree of hypocholesterolemia reproduces, in a parallel manner, the seriousness of the inflammatory response and metabolic dysregulation, abnormalities in cytokine level, gravity of illness and organ dysfunction, and it has a negative predictive value ${ }^{35,61,79-86}$.

In a large cohort of hospitalized patients who had cholesterol levels $<2.6 \mathrm{mmol} / \mathrm{L}$, a ten-fold higher mortality was reported, which inversely correlated with cholesterol levels ${ }^{87}$. Low serum cholesterol levels on admission to a surgical ICU have been found to be associated with a higher APACHE III and Multi-Organ Dysfunction Score (MODS), longer length of hospital stay, and higher mortality ${ }^{37}$. These data suggest that although total and HDL cholesterol levels fall with acute illness, the low cholesterol levels may predispose critically ill patients to endotoxemia, sepsis and MODS.

An important clinical observation has been that in critically ill patients with hypocholesterolemia there is progressive increase in cholesterol concomitantly with the general improvement of the clinical condition; therefore repeated cholesterol determinations may provide useful information on the course of the disease ${ }^{35}$. In this context it is also interesting that pre-operative hypocholesterolemia 
in surgical patients is connected with higher post-operative risk of septic complications ${ }^{77}$.

In patients with prolonged septic shock, absolute or relative adrenal insufficiency is found ${ }^{80}$. This phenomenon can be explained by the central role of cholesterol in the production of adrenal hormones, primarily cortisol.

Specifically, low levels of HDL may lead to adrenal insufficiency in critically ill patients. Adrenal insufficiency is being recognized with increasing frequency in critically ill patients: a reported incidence of up to $61 \%$ in patients who experience septic shock ${ }^{89,90}$. The mechanisms that lead to reversible adrenal failure of the critically ill are poorly understood. However, low HDL levels may play an important role ${ }^{88}$.

The adrenal gland does not store cortisol: increased secretion occurs because of increased synthesis controlled by adrenocorticotropin (ACTH). Cholesterol is the principal precursor for steroid biosynthesis in steroidogenic tissue. In a number of sequential enzymatic steps, cholesterol is metabolized by $\mathrm{P} 450$ cytochromes to aldosterone, dehydroepiandrosterone, androstenedione, and cortisol. The first and rate-limiting step is the formation of pregnenolone from cholesterol. At rest and during stress about $80 \%$ of circulating cortisol is derived from plasma cholesterol: the remaining $20 \%$ is synthesized in situ from acetate and other precursors ${ }^{91}$. Experimental studies suggest that HDL is the preferred cholesterol source of steroidogenic substrate in the adrenal gland ${ }^{92}$.

Besides the reparative role in the restoration of damaged cell membranes, cholesterol also plays an important role in organization and development of tissues and organs. This is demonstrated for instance by the so-called Smith-Lemli-Opitz syndrome. In the case of cholesterol insufficiency during development, the function of the protein which regulates the developmental gene $\mathrm{SHH}$ (Sonic hedgehog) is impaired. This gene is responsible for the proper development of tissues and for the organization of embryonic tissue. $\mathrm{SHH}$ regulating protein must bind to cholesterol to be active ${ }^{93}$.

Hypocholesterolemia is also related to decreases in some plasma proteins. Direct relationships between cholesterol and albumin, total protein, prealbumin, retinol-binding protein, transferrin, iron binding capacity, cholinesterase, and prothrombin activity have recently been confirmed ${ }^{34,82,84,94,95}$.

These relationships can be explained by hemodilution acting concomitantly on cholesterol and on the other variables, by the release of mediators and cytokines of the acute phase response, and by impaired liver synthesis or insufficiency of substrate.

An example of the cumulative impact of various adverse factors in decreasing cholesterol is patients after liver resection, in whom hypocholesterolemia is additively related to the magnitude of the operation, hemodilution from blood loss, liver dysfunction, sepsis and hypoalbuminemia ${ }^{96}$. This may explain how the degree of hypocholesterolemia often turns into a cumulative index of severity of illness, with prognostic implications. It is worth noting that the degree of hypocholesterolemia may be moderated by the simultaneous presence of cholestasis.
There is a well-known relationship between hypocholesterolemia and undernourishment. Hypocholesterolemia was experimentally induced by a low-protein diet, and on the other hand, alleviated by parenteral supplementation of amino acids, mainly branched-chain amino acids ${ }^{82}$. The principal factors to concomitantly decrease cholesterol and many plasma proteins are connected with the acute phase response. This is supported by the fact that most of the listed proteins represent "negative" acute phase reactants and that hypocholesterolemia is related, on the other hand, to an increase in "positive" acute phase reactants.

As hypocholesterolemia is associated with a poor outcome during critical illness, it could be postulated that patients who receive statins (3-hydroxy-3-methylglutaryl Coenzyme A reductase inhibitors) (HMG-CoA) have a poor outcome when critically ill. Emerging data, however, suggest that statins may improve the outcome of patients with sepsis. This effect is independent of the effect of statins on the lipid profile. Statins have been shown to have diverse anti-inflammatory and immunomodulating properties ${ }^{97}$. The HMG-CoA reductase inhibitor simvastatin has been shown to significantly improve survival in a murine model of sepsis ${ }^{98}$. In a prospective observational study treatment with a statin for greater than one month before the onset of an acute bacterial infection was found to be associated with a reduced rate of severe sepsis and ICU admission, despite the fact that the patients receiving statins had a significantly higher frequency of comorbidities ${ }^{99}$. Additional studies, however, are required before statins can be recommended for the treatment of sepsis.

\section{CONCLUSION}

Hypocholesterolemia is commonly observed in critically ill patients and in other acute or chronic conditions. In these patients, it is often an index of a pathophysiological frailty and impending danger. It may also reflect incapacity of the organism to increase cholesterol availability, to meet increased requirements in critical illness. Nevertheless, it is not known whether it is a secondary manifestation of disease, or whether it actively contributes to deterioration of the disease. Cholesterol seems to be a potentially essential component of nutrition, particularly in critically ill patients, where, due to the absence of cholesterol in parenteral nutrition, its exogenous supply is discontinued. However, the extent of contribution of impaired endogenous synthesis to hypocholesterolemia is not yet well-defined. The relationship between plasma cholesterol patterns and severity of illness is also important. In many hospital wards, progressive reversal of hypocholesterolemia is considered a marker of reversal of critical illness, and of patient recovery; likewise, severe persistent hypocholesterolemia, or further extreme drop in cholesterol, is a strongly unfavourable prognostic sign.

Although the contribution of hypocholesterolemia to mortality is modest compared with known risk factors such as increased severity of illness and the development of nosocomial infection, low serum lipid concentrations 
represent a potential therapeutic target in sepsis. What remains unclear is whether treatment which increases HDL or total cholesterol prevents or limits complications and improves the outcome of critically ill patients.

At present, the only concrete consequence of hypocholesterolemia is the imperative and rapid resolution of the underlying illness. Nevertheless, research in this field is continuing, and the enrichment of fat emulsions used in parenteral nutrition with cholesterol may be a new promising tool to influence hypocholesterolemia and the related undesirable effects in critically ill patients. This approach is being investigated in ongoing clinical trials.

\section{ACKNOWLEDGEMENTS}

This article is supported by grant project IGA NR /8921-3.

\section{REFERENCES}

1. Murray RK, et al. Harper's Biochemistry, 23. ed, Appleton and Lange, a Publishing Division of Prentice-Hall International, Connecticut, 1993.

2. Altmann SW, Davis HR, Zhu I, et al. Niemann-Pick C1 Like 1 protein is critical for intestinal cholesterol absorption. Science 2004 303:1201-1204.

3. Davis HR, Zhu I, Hoos LM, et al. Niemann-Pick C1 Like 1 (NPCL) is the intestinal phytosterol and cholesterol transporter and a key modulator of whole body cholesterol homeostasis. J. Biol Chem 2004; 279:33486-33592

4. Levy E, Schohraya S, Sinnett D, et al. Intestinal cholesterol transport proteins: an update and beyond. Curr Opinion in Lipid 2007; 18:310-318.

5. Bietrix F, Yan D, Nauze M, et al. Accelerated lipid absorption in mice overexpressing intestinal SR-BI J. Biol Chem 2006; 281:72147219.

6. Nauli AM, Nassir F, Zheng, et al. CD 36 is important for chylomicron formation and secretion and may mediate cholesterol uptake in the proximal intestine. Gastroenterology 2006; 131:1197-1207.

7. Kramer W, Girbig F, Corsiero D, et al. Aminopeptidase N (CD13) is a molecular target of the cholesterol absorption inhibitor ezetimibe in the enterocyte brush border membrane. J Biol. Chem 2005; 280:1306-1320.

8. Repa JJ, Berge KE, Pomajzl C, et al. Regulation of ATP-binding cassette sterol transporters $\mathrm{ABCG} 5$ and $\mathrm{ABCG}$ by the liver $\mathrm{X}$ receptors alpha and beta. J. Biol Chem 2002; 277:18793-18800.

9. Van der Veen JN, Kruit JK, Havinga R, et al. Reduced cholesterol absorption upon PPAR delta activation coincides with decreased intestinal expression of NPC1L1. J Lipid Res 2005; 46:526-534.

10. Gibbons GF, Mitropoulos KA, Myant NB. Biochemistry of cholesterol. Elsevier Biomedical Press, Amsterdam-New York-Oxford, 1982.

11. Rawson RB. The SREBP pathway-insights from Insigs and insects. Nat Rev MolCell Biol 2003; 4:631-640.

12. Horton JD, Goldstein JL, Brown MS. SREBPs: activators of the complete program of cholesterol and fatty acid synthesis in the liver, J. Clin. Invest. 2002; 109:1125-1131.

13. Acton S, Rigotti A, Landschulz KT, et al. Identification of scavenger receptor SR-BI as a high-density lipoprotein receptor. Science 271:518-520.

14. Attie AD, Kastelein JP, Hayden MR. Pivotal role of ABCA1 in reverse cholesterol transport influencing HDL levels and susceptibility to atherosclerosis. J. Lipid Res. 2001; 42:1717-1726.

15. Lo Sasso G, Petruzelli M, Moschetta A. A translational view on the biliary lipid secretory network. Biochem Biophys Acta 2008, in press, doi:10.1016/j.bbalip.2007.12.002.
16. Porter JA, Young KE, Beachy PA . "Cholesterol modification of hedgehog signaling proteins in animal development". Science 274(5285):255-259.

17. Avigan J, Steinberg D. Sterol and bile acid excretion in man and the effects of dietary fat. J. Clin Invest 1965; 44:1845-56.

18. Parker TS, McNamara DJ, Brown CD et al. Plasma mevalonate as a measure of cholesterol synthesis in man. J. Clin. Invest. 1984; 74:795-804.

19. Hyšpler R, Crhová S, Gasparič J, et al. Determination of isoprene in human expired breath using solid-phase microextraction and gas chromatography-mass spectrometry. J Chromatogr B Biomed Sci Appl. 2000; 28:183-90.

20. Miettinen TA. Diurnal variation of cholesterol precursors squalene and methyl sterols in human plasma lipoproteins. J. Lipid Res. 1982; 23:466-473.

21. Bjorkhem I, Miettinen T, Reihner E, et al. Correlation between serum levels of some cholesterol precursors and activity of HMGCoA reductase in human liver. J. Lipid Res. 1987; 28:1137-43.

22. Jones PJH. Regulation of cholesterol biosynthesis by diet in humans. Am. J. Clin. Nutr. 1997; 66:438-46.

23. Taylor CB, Mikkelson B, Anderson JA, et al. Human serum cholesterol synthesis measured with the deuterium label. Arch. Path.1966; 81:213-31.

24. Jones JP, Pappu AS, Illingworth DR, et al. Correspondence between plasma mevalonic acid levels and deuterium uptake in measuring human cholesterol synthesis. Eur. J. Clin. Invest. 1992; 22:609-20

25. Beylot M. Use of stable isotopes to evaluate the functional effects of nutrients.Curr Opin Clin Nutr Metab Care. 2006; 9(6):734-9.

26. Kuksis A. Plasma non-cholesterol sterols. Journal of Chromatography A 2001; 935:203-236.

27. Thannhauser SJ, Schaber H. Uber bezie-hungen des gleichgewichtes cholesterin und cholesterinester im blut und serum zur leberfunkton. Klin Wochenschr 1926; 7:252-3.

28. Alvarez C, Ramos A. Lipids, lipoproteins and apoproteins in serum during infection. Clin Chem 1986; 32:142-5.

29. Coombes EJ, Shakespeare PG, Batstone GF. Lipoprotein changes after burn injury in man. J Trauma 1980; 20:971-5.

30. Budd D, Ginsberg H. Hypocholesterolemia and acute myogenous leukemie: association between disease activity and plasma low density lipoprotein cholesterol concentrations. Cancer 1986; 58:1361-5.

31. Goichot B, Schlienger JL, Grunenberger F, et al. Low cholesterol concentrations in free-living elderly subjects: Relations with dietary intake and nutritional status. Am J Clin Nutr 1995; 62(3):547.

32. Bakalar B, Zadak Z, Pachl J. Severe hypocholesterolemia is associated with adrenal insufficiency in multiple trauma patients. Intens Care Med 2001; 27(S2):S253.

33. Marik PE. Dyslipidemia in the critically ill. Crit Care Clin 2006; 22:151-159.

34. Lopez-Martinez J, Sanchez-Castilla M, Garcia-de-Lorenzo A: Hypocholesterolemia in critically ill patients. Intensive Care Med 2000; 26:259-60.

35. Giovannini I, Boldrini G, Chiarla C, et al. Pathophysiologic correlates of hypocholesterolemia in critically ill surgical patients. Intensive Care Med 1999; 25:748-751.

36. Gordon BR, Parker TS, Levine DM, et al. Low lipid concentrations in critical illness: implications for preventing and treating endotoxemia. Crit Care Med 1996; 24:584-9.

37. Gordon BR, Parker TS, Levine DM, et al. Relationship of hypolipidemia to cytokine concentrations and outcomes in critically ill surgical patients. Crit Care Med. 2001; 29: 1563-8.

38. Akgun S, Ertel NH, Mosenthal A, et al. Postsurgical reduction of serum lipoproteins: Interleukin-6 and the acute-phase response. J Lab Clin Med 1998:131:103-8.

39. Diederich W, Orso E, Dronik W, et al. Apolipoprotein A1 and HDL3 inhibit spreading of primary human monocytes through a mechanism that involves cholesterol depletion and regulation of CDC 42. Atherosclerosis 2001; 159:313-24.

40. Ruan XZ, Varghese Z, Powers SH, et al. Dysregulation of LDL receptor under the influence of inflammatory cytokines: A new pathway for foam cell formation. Kidney Int 2001; 60:2037-38. 
41. de Beer FC, Connel PM, Yu J, et al. HDL modification by secreting phospholipase A2 promotes scavenger receptor class B type 1 interaction and accelerates HDL catabolism. J Lipid Res 2000; 41:1849-57.

42. Leonarduzzi G, Arkaw MC, Basaga H, et al. Lipid oxydation products in cell signaling. Free Radic Biol Med 2000; 28:1370-78.

43. Buechler C, Ritter M, Quoc CD,et al. Lipopolysaccharide inhibits the expression of the scavenger receptor Cla-1 in human monocytes and macrophages.Biochem Biophys Commun 1999; 262:251-54.

44. Gierens H, Nauck M, Roth M, et al. Interleukin-6 stimulates LDL receptor gene expression via activation of sterol-responsive and Sp1 binding elements. Atheroscler Thromb Vasc Biol 2000; 20:1777-83.

45. Roth G, Kotzka J, Kremer L, et al. MAP kinases Erkl/2 phosphorylate sterol regulatory binding-element protein (SREBP)-1a at serine 117 in vitro. Jbiol Chem 2000; 275:33302-307.

46. van Leeuwen HJ, Heezius EC, Dallinga GM, et al. Lipoprotein metabolism in patients with severe sepsis. Crit Care Med 2003; 31:1359-66.

47. Fraunberger P, Schaefer S, Werdan K, et al. Reduction of circulating cholesterol and apolipoprotein levels during sepsis. Clin Chem Lab Med 1999; 37: 357-62.

48. Mentz MH, Magnette J. Hypocholesterolemia during the acute phase of an inflammatory reaction of infectious origin.120cases. Rev Med Interne 1998; 19:168-72.

49. Fraunberger P, Pilz G, Cremer P, et al. Association of serum tumor necrosis factor levels with decrease of cholesterol during septic shock. Shock1998; 10:359-63.

50. Dunham CM, Fealk MH, Sever WE. Following severe injury, hypocholesterolemia improves with convalescence but persists with organ failure or onset of infection. Crit Care 2003; 7:R145-53.

51. Ettinger WH, Varma VK, Sorci-Thomas M, et al. Cytokines decrease apolipoprotein accumulation in medium from Hep G2 cells. Arterioscler Thromb 1994; 14:8-13.

52. Spriggs DR, Sherman ML, Michie H. Recombinant human tumor necrosis factor administered as a 24-hour intravenous infusion: a phase 1 pharmacologic study. J Natl Cancer Inst 1988; 80:1039-44.

53. van Gameren MM, Willemse PH, Mulder NH. Effects of recombinant human interleukin-6 in cancer patients: a phase I-II study. Blood 1994; 84:1434-41.

54. Memon RA, Staprans I, Noor M, et al. Infection and inflammation induce LDL oxidation in vivo. Arterioscler Thromb Vasc Biol 2000; 20:1536-42.

55. Tietge UJ, Maugeais C, Cain W,et al. Overexpression of secretory phospholipase $\mathrm{A}_{2}$ causes rapid catabolism and altered tissue uptake of high-density lipoprotein cholesterol ester and lipoprotein A-1. J Biol Chem 2000; 275:10077-84.

56. Panousis CG, Zuckerman SH. Interferon-gamma induces downregulation of Tangier disease gene (ATP-binding-cassette transporter1) in macrophage-derived foam cells. Arterioscler Thromb Vasc Biol 2000; 20:1567-71.

57. Feingold KR, Soued M, Adi S, et al. Tumor necrosis factor increased hepatic very-low-density lipoprotein production and increased serum triglyceride levels in diabetic rats. Diabetes 1990; 39:1569-74.

58. Feingold KR, Serio MK, Adi S, et al. Tumor necrosis factor stimulates hepatic lipid synthesis and secretion. Endocrinology 1989; 124:2336-42.

59. Robin AP, Askanazi J, Greenwood MR, et al. Lipoprotein lipase activity in surgical patients: influence of trauma and infection. Surgery 1981; 90:401-8.

60. Beutler B, Mahoney J, Le TN, et al. Purification of cachectin, a lipoprotein lipase-suppressing hormone secreted by endotoxin-induced RAW 264.7 cells. J Exp Med 1985; 161:984-95.

61. Bonville DA, Parker TS, Levine DM, et al. The relationship of hypocholesterolemia to cytokine concentrations and mortality in critically ill patients with systemic inflammatory response syndrome. Surg Infect 2004; 5:39-49.

62. Freudenberg MA, Bog-Hansen TC, Back U. Interaction of lipopolysaccharides with plasma high-density lipoprotein in rats. Infect Immun 1980; 28:373-380.
63. Levine DM, Parker TS, Donelly TM, et al. In vivo protection against endotoxin by plasma high density lipoprotein. Proc Natl Acad Sci USA 1993; 90:12040-12044.

64. Ulevitch RJ, Johnson AR, Weinstein DB. New function for high density lipoproteins. Isolation and characterization of a bacterial lipopolysaccharide -high-density lipoprotein complex formed in rabbit plasma. J Clin Invest. 1981; 67(3):827-37.

65. Harris HW, Grunfed C, Feingold KR, et al. Chylomicrons alter the fate of endotoxin, decreasing tumor necrosis factor release and preventing death. J Clin Invest 1993; 91:1028-34.

66. Parker TS, Levine DM, Chang JC, et al. Reconstituted high-density lipoprotein neutralizes gram-negative bacterial lipopolysaccharides in human whole blood. Infect Immun 1995; 63:253-58.

67. Casas AT, Hubsch AP, Rogers BC, et al. Reconstituted high-density lipoprotein reduces LPS-stimulated TNF alpha. J Surg Res 1995; 59:544-552.

68. Hubsch AP, Powell FS, Lerch PG, et al. A reconstituted, apolipoprotein A-1 containing lipoprotein reduces tumor necrosis factor release and attenuated shock in endotoxemic rabbits. Circ Shock 1993; 40:14-23.

69. Hubsch AP, Casas AT,Doran JE. Protective effects of reconstituted high-density lipoprotein in rabbit gram-negative bacteremia models. J Lab Clin Med 1995; 126:548-558.

70. Casas AT, Hubsch AP, Doran JE. Effects of reconstituted high-density lipoprotein in persistent gram-negative bacteremia. Am Surg 1996; 62:350-355.

71. Goldfarb RD, Parker TS, Levine DM, et al. Protein-free phospholipid emulsion treatment improved cardiopulmonary function and survival in porcine sepsis. Am J Physiol Regul Integr Comp Physiol 2003; 284:R550-R557.

72. Malyszko J, Urano T, Knofler R, et al. Relationships between serum lipids, serotonin, platelet aggregation and some fibrinolytic parameters in humans. Life Sci 1994; 55:1619-23.

73. Koller R, Koller F, Binder BR. Purification and identification of the lipoprotein-binding proteins from human blood platelet membrane. J Biol Chem 1989; 264:12412-418.

74. Pajkrt D, Lerch PG, van der PT, et al. Differential effects of reconstituted high-density lipoprotein on coagulation, fibrinolysis and platelet activation during human endotoxemia. Thromb Haemost 1997; 77:303-7.

75. Barie PS, Hydo LJ, Fischer E. Comparison of APACHE II and III scoring systems for mortality prediction in critical surgical illness. Arch Surg 1995; 130:77-82.

76. Sankaran RT, Mattana J, Pollack S, et al. Laboratory abnormalities in patients with bacterial pneumonia. Chest 1997; 111:595-600.

77. Leardi S, Altilia F, Delmonaco S, et al. Blood levels of cholesterol and postoperative septic complications. A. Chir Ital 2000; 71:233237.

78. Iribarren C, Jacobs DR, Sidney S, et al. Cohort study of serum total cholesterol and in- hospital incidence of infections diseases. Epidemiol Infect 1998; 121:335-47.

79. Muldoon MF, Marsland A, Flory JD, et al. Immune system differences in men with hypo- or hypercholesterolemia. Clin Immunol Immunopathol 1997; 84:145-149.

80. Chenaud C, Merlani PG, Roux-Lombard P, et al. Low apolipoprotein A-I level at intensive care unit admission and systemic inflammatory response syndrome exacerbation. Crit Care Med 2004; 32:632-637.

81. Chernow B. Variables affecting outcome in critically ill patients. Chest 1999; 115:71S-76S.

82. Chiarla C, Giovannini I, Siegel JH, et al. Relationship of plasma cholesterol to doses of branch-chain amino acids in sepsis. Crit Care Med 1990; 18:32-36.

83. Chiarla C, Giovannini I, Siegel JH, et al. Relationship of plasma acute-phase protein to amino acid levels during high-dose branched chain amino acid support in sepsis. In: Faist E, Meakins JL, Schildberg FW editors. Host Defense Dysfunction in Trauma, Shock and Sepsis. Berlin Heidelberg New York: Springer; 1993; 1030-1034.

84. Chiarla C, Giovannini I, Siegel JH, et al. The relationship between plasma taurine and other amino acid levels in human sepsis. J Nutr 2000; 130:2222-2227. 
85. Druml W. Is cholesterol a conditionally essential nutrient in critically ill patients. Wien Klin Wochenschr 2003; 115/21-22:740-742.

86. Fraunberger P, Nagel D, Walli AK, et al. Serum cholesterol and mortality in patients with multiple organ failure. Crit Care Med 2000; 28:3574-3575.

87. Windler E, Ewers-Grabow U, Thiery J, et al. The prognostic value of hypocholesterolemia in hospitalized patients. Clin Invest 1994 72:939-43.

88. Marik PE. Adrenal insufficiency: the link between low Apolipiprotein A-1 levels and poor outcome in the critically ill? Crit Care Med 2004; 32:1977-8.

89. Marik PE, Zaloga GP. Adrenal insufficiency in the critically ill: a new look at an old problem. Chest 2002; 122:1784-96.

90. Marik PE, Zaloga GP. Adrenal insufficiency during septic shock. Crit Care Med 2003; 31:141-5.

91. Borkowski AJ, Levin S, Delcroix C, et al. Blood cholesterol and hydrocortisone production in man: quantitative aspects of the utilization of circulating cholesterol by the adrenals at rest and under adrenocortocotropin stimulation. Clin Invest 1967; 46:797-811.

92. Yaguchi H, Tsutsumi K, Shimono K, et al. Involvement of high-density lipoprotein as substrate cholesterol for steroidogenesis by bovine adrenal fasciculo-reticularis cells. Life Sci 1998; 62:1387-95.
93. Roux C, Wolf C, Mulliez N, et al. Role of cholesterol in embryonic development. Am J Clin Nutr 2000; 71(S):1270S-1279S.

94. Chiarla C, Giovannini I, Siegel JH. The relationship between plasma cholesterol, amino acids and acute phase proteins in sepsis. Amino Acids 2004; 27(1):97-100.

95. Giovannini I, Chiarla C, Giuliante F, et al. The relationship between albumin, other plasma proteins and variables, and age in the acute phase response after liver resection in man. Amino Acids 2006; 31:463-469.

96. Giovannini I, Chiarla C, Greco F, Boldrini G, Nuzzo G. Characterization of Biochemical and Clinical Correlates of Hypocholesterolemia after Hepatectomy. Clin Chem; 2003; 49(2):317-319.

97. Blanco-Colio LM, Tunon J, Martin-Ventura JL, et al. Anti-inflammatory and immunomodulatory effects of statins. KidneyInt 2003; 63:12-23.

98. Merx MW, Liehn EA, Janssens U et al. HMG-Co-A reductase inhibitor simvastatin profoundly improves survival in a murine model sepsis. Circulation 2004; 109:2560-65.

99. Almong Y, Shefer A, Novack V, et al. Prior statin therapy is associated with a decreased rate of severe sepsis. Circulation 2004; 110:880-85. 
